\title{
Correction to: Functional Analysis of Long Non-Coding RNAs
}

\section{Haiming Cao}

\section{Correction to:}

Haiming Cao (ed.), Functional Analysis of Long Non-Coding RNAs:

Methods and Protocols, Methods in Molecular Biology, vol. 2254, https://doi.org/10.1007/978-1-0716-1158-6

In the original version of this book, Chapter 8 was inadvertently published without labelling Yang Ding as the co-corresponding author. This has now been rectified in this revised version of the book.

In the original version of Chapter 9 of this book, the affiliation for Barbara UszczynskaRatajczak is incomplete.

"Institute of Bioorganic Chemistry Polish Academy" should read "Institute of Bioorganic Chemistry Polish Academy of Sciences". 